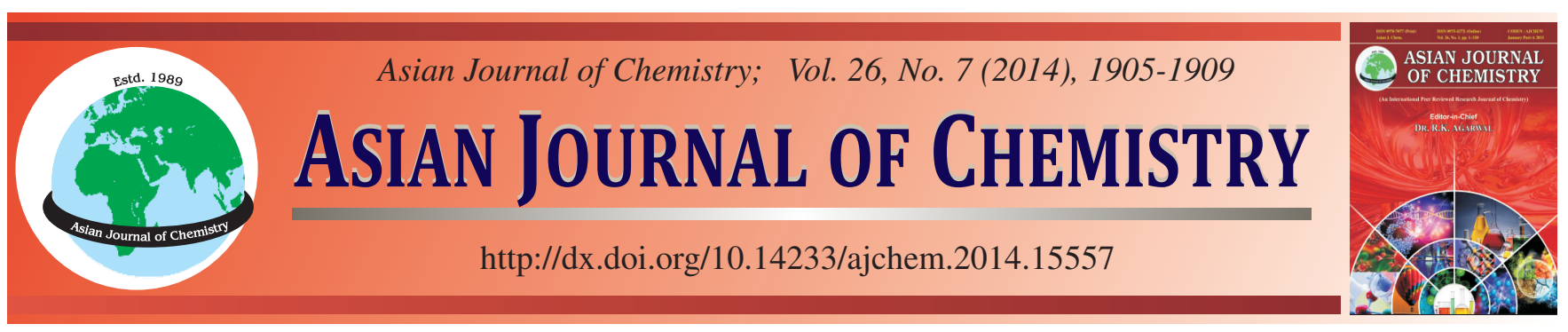

\title{
Simultaneous Determination of Sulfonamides in Honey by Dispersive Liquid-liquid Microextraction Combined with High-Performance Liquid Chromatography
}

\author{
Xiaofeng Chi, Guoying Zhang, Yuancan Xiao, Qi Dong and Fengzu Hu*
}

Northwest Institute of Plateau Biology of Chinese Academy of Sciences, No. 23 Xingning Road, Xining 810008, P.R. China

*Corresponding author: Tel/Fax: +86 971 6132750; E-mail: xfchi@nwipb.ac.cn

\begin{abstract}
Dispersive liquid-liquid microextraction combined with high-performance liquid chromatography-diode array detection has been successfully developed for the extraction and determination of sulfonamides in honey samples. The effects of parameters such as the nature and volume of extraction solvent and dispersive solvent, extraction time, ionic strength and solution $\mathrm{pH}$ were investigated. In this method, $1 \mathrm{~mL}$ of acetonitrile (as dispersive solvent) containing $40 \mu \mathrm{L}$ of 1,1,2,2-tetrachloroethane (as extraction solution) was rapidly injected into a $5 \mathrm{~mL}$ honey sample containing the analytes, thereby forming a cloudy solution. After extraction, phase separation was performed by centrifugation and the enriched analytes in the sedimented phase were determined by HPLC-DAD. Under the optimal conditions, the detection limit of the method was 0.8-1.7 $\mu \mathrm{g} \mathrm{kg}^{-1}$ and the relative standard deviations (RSD \%) for determination of the sulfonamides were in the range of $0.172-1.549 \%$. Linearity was found to be in the range of $0.1-10.0 \mu \mathrm{g} \mathrm{mL}{ }^{-1}$; also, the enrichment factors were in the range of 42-81. Finally, the method was applied to determine the trace amounts of the sulfonamides in real honey sample and satisfactory results were obtained.
\end{abstract}

Keywords: Dispersive liquid-liquid microextraction, Sulfonamides, HPLC, Honey.

\section{INTRODUCTION}

Sulfonamides are extensively used in veterinary practice for the treatment of various bacterial infections. Use of sulfonamides in food producing animals may result in sulfonamide residues being present in the edible products. The European Community has established maximum residue limits for sulfonamides in foods of animal origin at $0.1 \mathrm{ppm}$ to ensure the safety of food to the consumers ${ }^{1}$. Honey bee larvae are susceptible to American foulbrood or European foulbrood, disease caused by the organism Bacillus larvae, which can devastate hives. Sulfonamides are relatively stable chemotherapeutics known to control this disease ${ }^{2}$ but they are not permitted to use for this purpose in most countries. Nevertheless, due to their low price and steady antibiosis effectiveness, illegal use of sulfonamides still exists. So, it is very important to develop a sensitive, rapid and simple method for the determination of sulfonamides.

Up to now, a variety of analytical methods have been used to measure sulfonamide residues in biological materials. The main approaches for identification and quantification of sulfonamide residues include: enzyme immunoassay ${ }^{3-5}$, thin-layer chromatography $^{6,7}$ and liquid chromatography ${ }^{8-10}$. Aiming of cleaning up and concentrating the analytes of interest and rendering them in a compatible form with the analytical system, sample-preparation step is commonly involved before instrumental analysis. Solid-phase extraction is routinely used for clean-up and preconcentration in the analysis of sulfonamide residues in honey samples ${ }^{8-10}$. Solid-phase extraction has the advantages of simplicity, speed and less consumption of organic solvents. However, generic sorbents usually lack selectivity and are easily subjected to interference by non-target substances with similar characteristics. Although immune affinity chromatography (IAC) is capable of differentially adsorbing target analytes, it still has some disadvantages such as lack of stability and high costs of antibody preparation.

Recently, Assadi and coworkers proposed a novel modality of liquid-phase microextraction (LPME) termed as dispersive liquid-liquid microextraction (DLLME) ${ }^{11}$, which is based on a ternary component solvent system like homogeneous liquidliquid extraction and cloud point extraction. This method has been successfully applied for the preconcentration of organic and inorganic species in environmental samples such as antioxidants $^{12}$, chloramphenicol $^{13}$, pentachlorophenol ${ }^{14}$, psychotropic drugs ${ }^{15}$, bisphenol-A ${ }^{16}$, cadmium $^{17}$, copper $^{18}$, palladium $^{19}$, etc. In this method, the appropriate mixture of extraction solvent and dispersive solvent is injected into aqueous sample rapidly by syringe and a cloudy solution is formed. Extraction 
of the analytes from aqueous sample into the dispersed organic droplets takes place. After extraction, phase separation is performed by centrifugation; analytes in the sedimented phase can be determined by analytical instruments. The principal advantage of DLLME is the very short extraction time because of the quickly equilibrium state achievement. Other advantages of DLLME include simplicity of operation, rapidity, low cost, high recovery, high enrichment factor and environmental benignity.

The aim of this work is to develop a new method combined DLLME for the simultaneous determination of sulfonamides by high-performance liquid chromatography (HPLC) with diode array detection (DAD) in honey samples. The effects of various experimental parameters, such as the kind and volume of extraction solvent and dispersive solvent, extraction time, salt effect and $\mathrm{pH}$ were studied and optimized. The optimized method was applied to determine sulfonamides in honey samples to evaluate the application of this method to real samples.

\section{EXPERIMENTAL}

The reference standard of sulfanilamide, sulfacetamide, sulfadiazine, sulfathiazole, sulfapyridine, sulfamerazine, sulfameter, sulfamethizol, sulfamethazine, sulfamethoxypyridazine, sulfachloropyridazine, sulfamethoxazole, sulfamonomethoxide sodium hydrate, sulfadoxine and sulfisoxazole were purchased from the National Institute for the Control of Pharmaceutical and Biological Products (Beijing, China).

Acetonitrile was of HPLC grade (Fisher chemical Co., Inc., Iowa, CA, USA). Dichloromethane , chloroform, carbon tetrachloride, dichloroethane, 1,1,2,2-tetrachloroethane, acetone, sodium chloride were all of analytical grade. Water was purified on a Milli-Q system (Millipore, Bedford, MA) and used throughout the study.

The standard of three contents were accurately weighed and then dissolved in acetonitrile to produce stock solutions, which were diluted to appropriate concentration for the construction of calibration curves. All standard solutions were kept at $4{ }^{\circ} \mathrm{C}$ in the refrigerator.

$1 \mathrm{~g}$ of honey was weighed into a $10 \mathrm{~mL}$ centrifuge tube with conical bottom and $5 \mathrm{~mL}$ of water was added and the mixture was sonicated until a homogeneous sample was obtained. Then, the homogeneous sample was used for DLLME-HPLC analysis directly.

Chromatographic conditions: The HPLC system of Agilent 1260 was used for the analysis. Chromatographic separation of three compounds was achieved on a Kromasil $\mathrm{C}_{18}(250 \times 4.6 \mathrm{~mm}, 5 \mu \mathrm{m})$ column. The temperature of the column was maintained at $30^{\circ} \mathrm{C}$. The mobile phase consisted of solvent A (acetonitrile) and B (deionized water). A gradient elution program was used as follows: 0-30 min 10-45 \% A (v/v, linear gradien) with the flow rate of $1 \mathrm{~mL} \mathrm{~min}^{-1}$.

Extraction procedure: A $5 \mathrm{~mL}$ homogeneous honey solution containing the analytes was placed in a $10 \mathrm{~mL}$ glass tube with conical bottom. Acetonitrile $(1 \mathrm{~mL})$ as dispersive solvent, containing $40 \mu \mathrm{L} \mathrm{C}_{2} \mathrm{H}_{2} \mathrm{Cl}_{4}$ as extraction solvent, was injected rapidly into the sample solution. And then the mixture was vortexed for $1 \mathrm{~min}$ at $2000 \mathrm{rpm}$. After vortexing, the cloudy solution that consists of very fine droplets of $\mathrm{C}_{2} \mathrm{H}_{2} \mathrm{Cl}_{4}$ dispersed into sample solution was formed and the analytes was extracted into the fine droplets. After centrifugation for $2 \mathrm{~min}$ at 4000 $\mathrm{rpm}$, clear phase separation of the mixed solution was obtained. $10 \mu \mathrm{L}$ of the organic phase was directly injected to the HPLCDAD system.

\section{RESULTS AND DISCUSSION}

In this study dispersive liquid-liquid microextraction combined with HPLC-DAD was used for preconcentration and determination of the three sulfonamides in honey samples. To obtain a high recovery and enrichment factor, several parameters that influence the extraction efficiency had to be studied and optimized. Such parameters included the type of dispersive and extraction solvents their volumes, salt addition, $\mathrm{pH}$. In order to study the mentioned factors, enrichment factor have been used to evaluate the extraction efficiency under different conditions. In DLLME the enrichment factor was defined as the ratio between the analyte concentration in the sedimented phase $\left(\mathrm{C}_{\text {sed }}\right)$ and the initial concentration of analyte $\left(\mathrm{C}_{0}\right)$ within the sample:

$$
\text { Enrichment factor }(\mathrm{EF})=\frac{\mathrm{C}_{\text {sed }}}{\mathrm{C}_{0}}
$$

Selection of extraction solvent: The selection of an appropriate extraction solvent is of great importance to the DLLME process. In the selection of extraction solvent, some properties must be considered such as (a) higher density than water, (b) good chromatographic behaviour, (c) extraction capability of interested compounds, (d) low solubility in water and (e) form a stable two-phase system in the presence of a dispersive solvent when injected to an aqueous solution. Based on these criteria, $\mathrm{CH}_{2} \mathrm{Cl}_{2}\left(1.32 \mathrm{~g} \mathrm{~mL}^{-1}\right), \mathrm{CHCl}_{3}\left(1.47 \mathrm{~g} \mathrm{~mL}^{-1}\right)$, $\mathrm{CCl}_{4}\left(1.59 \mathrm{~g} \mathrm{~mL}^{-1}\right), \mathrm{C}_{2} \mathrm{H}_{4} \mathrm{Cl}_{2}\left(1.25 \mathrm{~g} \mathrm{~mL}^{-1}\right)$ and $\mathrm{C}_{2} \mathrm{H}_{2} \mathrm{Cl}_{4}(1.54 \mathrm{~g}$ $\mathrm{mL}^{-1}$ ) were selected for the study. On the other hand, the selection of a dispersive solvent is limited to solvents such as acetone, methanol, ethanol and acetonitrile, which are miscible with both water and the extraction solvents and could form a cloudy state when injected with the organic extractant into water. In this study all combinations using $\mathrm{CH}_{2} \mathrm{Cl}_{2}, \mathrm{CHCl}_{3}$, $\mathrm{CCl}_{4}, \mathrm{C}_{2} \mathrm{H}_{4} \mathrm{Cl}_{2}, \mathrm{C}_{2} \mathrm{H}_{2} \mathrm{Cl}_{4},(40 \mu \mathrm{L})$ as extractant with acetone, acetonitrile and methanol $(1 \mathrm{~mL})$ as dispersive solvent were tested. In the case of $\mathrm{CH}_{2} \mathrm{Cl}_{2}$ and $\mathrm{C}_{2} \mathrm{H}_{4} \mathrm{Cl}_{2}$ as extraction solvents, a two-phase system was not observed with any studied dispersive solvents when they were injected to $5 \mathrm{~mL}$ sample solution. This is probably due to that the densities of $\mathrm{CH}_{2} \mathrm{Cl}_{2}$ and $\mathrm{C}_{2} \mathrm{H}_{4} \mathrm{Cl}_{2}$ are smaller than those of $\mathrm{CHCl}_{3}, \mathrm{CCl}_{4}$ and $\mathrm{C}_{2} \mathrm{H}_{2} \mathrm{Cl}_{4}$, and the miscibilities of $\mathrm{CH}_{2} \mathrm{Cl}_{2}$ and $\mathrm{C}_{2} \mathrm{H}_{4} \mathrm{Cl}_{2}$ in the organic solvents are higher than those of $\mathrm{CHCl}_{3}, \mathrm{CCl}_{4}$ and $\mathrm{C}_{2} \mathrm{H}_{2} \mathrm{Cl}_{4}$. It is not easy that $\mathrm{CH}_{2} \mathrm{Cl}_{2}$ and $\mathrm{C}_{2} \mathrm{H}_{4} \mathrm{Cl}_{2}$ deposited in the bottom of the test tube after spraying. In the case of with $\mathrm{CCl}_{4}$ as extraction solvent, no chromatographic peak can be found. This showed that $\mathrm{CCl}_{4}$ could not extract the analytes from sample solutions for it is non-polar solvent. In the case of $\mathrm{CHCl}_{3}$ only with acetonitrile as dispersive solvent, a two-phase system was well stable. With $\mathrm{C}_{2} \mathrm{H}_{2} \mathrm{Cl}_{4}$ as extraction solvent, a two-phase system was formed with all four dispersive solvents and its sedimented 


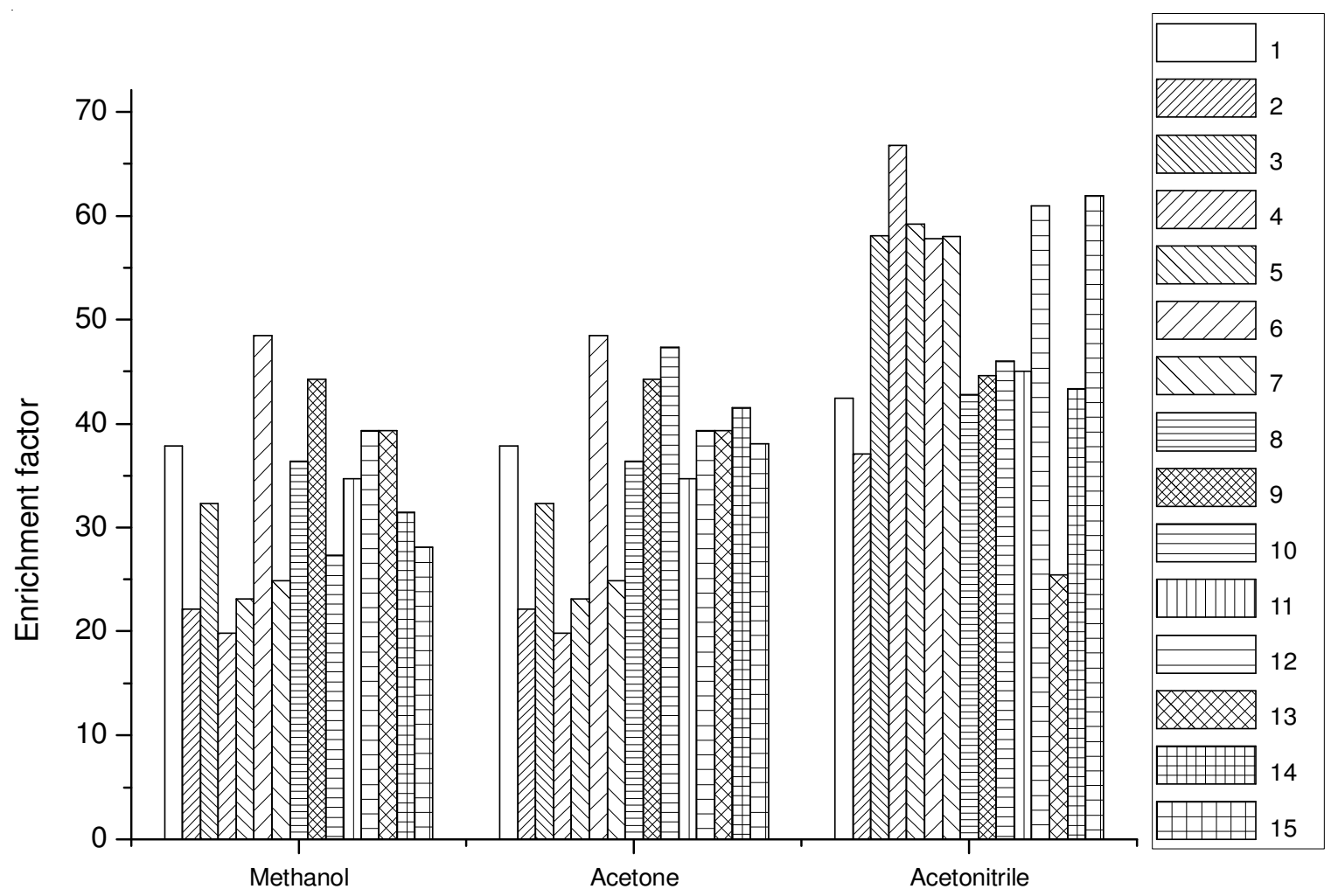

Fig.1. Effects of different dispersive solvents on enrichment factor of sulfonamides obtained from DLLME. Extraction conditions: water sample volume $5.00 \mathrm{~mL}$; extraction solvent $\left(\mathrm{C}_{2} \mathrm{H}_{2} \mathrm{Cl}_{4}\right)$ volume $40.0 \mu \mathrm{L}$. sulfanilamide (1), sulfacetamide (2), sulfadiazine (3), sulfathiazole (4), sulfapyridine (5), sulfamerazine (6), sulfameter (7), sulfamethizol (8), sulfamethazine (9), sulfamethoxypyridazine (10), sulfachloropyridazine (11), sulfamethoxazole (12), sulfamonomethoxide sodium hydrate (13), sulfadoxine (14), sulfisoxazole (15)

phase can easily be removed by syringe to be introduced into the HPLC while has less consumption volume. Thereby, $\mathrm{C}_{2} \mathrm{H}_{2} \mathrm{Cl}_{4}$ was selected as the extraction solvent.

Selection of dispersive solvent: With $\mathrm{C}_{2} \mathrm{H}_{2} \mathrm{Cl}_{4}$ as extraction solvent, methanol, acetonitrile and acetone were tested as disperser solvent and the effect of these solvents on the performance of DLLME was investigated. The experiments were performed by using $1 \mathrm{~mL}$ of each dispersive solvent containing $40 \mu \mathrm{L} \mathrm{C}_{2} \mathrm{H}_{2} \mathrm{Cl}_{4}$ and three replicate tests were performed for each type of dispersive solvent. The effect of different dispersive solvents on the enrichment factor of phthalate esters were shown in (Fig. 1). As can be seen, enrichment factors for all analytes are higher using acetonitrile as dispersive solvent compared to other solvents. Giving an overall consideration, acetonitrile was selected as the dispersive solvent for subsequent studies.

Effect of volume of extraction solvent: In order to study the effect of extraction solvent volume on the extraction efficiency, several different volumes of $\mathrm{C}_{2} \mathrm{H}_{2} \mathrm{Cl}_{4}(10,20,30,40$, 50,60 and $70 \mu \mathrm{L}$ ) and a constant volume of dispersive solvent (acetonitrile, $1 \mathrm{~mL}$ ) were applied to perform DLLME. The results indicated that by increasing the volume of extraction solvent from 10 to $70 \mu \mathrm{L}$, the volume of sedimented phase increases from 12 to $100 \mu \mathrm{L}$, but a dramatic increase of enrichment factors was observed on all target analytes as the extraction solvent volume was increased from 10 to $40 \mu \mathrm{L}$ and a constant of decrease after $40 \mu \mathrm{L}$. because of the increasing of the volume of sedimented phase. Thereby, $40 \mu \mathrm{L} \mathrm{C}_{2} \mathrm{H}_{2} \mathrm{Cl}_{4}$ was used as extraction solvent in subsequent experiments.
Effect of volume of dispersive solvent: The dispersive solvent volume is another important factor that affects extraction efficiency in DLLME. The variation of disperser solvent volume causes changes in the volume of the sedimented phase. At low disperser volume, the organic extractant droplets cannot form properly which leads to low enrichment factors. At high disperser volume, the solubility of polar organic analytes in aqueous phase will increase. To avoid this problem, the influence of the volume of the disperser solvent acetonitrile $(0.2,0.4$, $0.6,0.8,1.0,1.2$ and $1.4 \mathrm{~mL}$ ) was investigated. The results showed that the extraction efficiency increases first until the volume reached to $1 \mathrm{~mL}$ and then decreases by increasing the volume of acetonitrile for all the analytes. The reason could be that, at a low volume of acetonitrile, a cloudy state could not be well formed, therefore, resulting in a low recovery. At a higher volume of acetonitrile, the solubility of the pesticides in water was increased, leading to decreased extraction efficiency because of a decrease in distribution coefficient. Based on the experimental results, $1 \mathrm{~mL}$ of acetone was chosen.

Effect of extraction time: Extraction time is one of the most important factors in most microextraction procedures, such as liquid-phase microextraction and solid phase microextraction. In DLLME, extraction time is defined as interval time between injecting the mixture of disperser solvent (acetonitrile) and extraction solvent $\left(\mathrm{C}_{2} \mathrm{H}_{2} \mathrm{Cl}_{4}\right)$ and before starting to centrifuge. In this work the influence of extraction time was investigated in the range 0-600 s with the other experimental conditions fixed. The experimental results showed that the variations of enrichment factor versus extraction time are not 
remarkable. It is revealed that the DLLME method is timeindependent. After the formation of cloudy solution, large surface area between extraction solvent and aqueous phase was formed. Thereby the transition of analyte from aqueous phase to extraction solvent is very fast and equilibrium state is achieved quickly. Similar observations were also reported by other researchers ${ }^{20,21}$. This short extraction time provides a remarkable advantage to perform DLLME for sample preparation.

Effect of ionic strength: To assess the influence of ionic strength on the extraction efficiency of DLLME, a series of experiments were performed by adding $\mathrm{NaCl}$ concentration in the range of $(0-12 \%, \mathrm{w} / \mathrm{v})$ with other experimental conditions kept constant. It was found that enrichment factors were increased as $6 \% \mathrm{NaCl}$ was applied and started being decreased for all analytes when $\mathrm{NaCl}$ concentration was higher than $6 \%$, meanwhile the organic phase became less dense when $8 \%$ or more $\mathrm{NaCl}$ was added into the system. The volume of the sedimented phase increases from 32 to $74 \mu \mathrm{L}$ by increasing the amount of $\mathrm{NaCl}$ from 0 to $6 \%$, because of the decrease of solubility of extraction solvent in aqueous phase. Based on these results, $6 \% \mathrm{NaCl}$ was chosen as the optimal salt concentration in the DLLME procedure.

Effect of the solution pH: The solution $\mathrm{pH}$ of the sample is a significant factor, which may affect the extraction recoveries of sulfonamides in the samples. In this experiment, effect of $\mathrm{pH}$ on the extraction performance within the range of $\mathrm{pH}$ 2-10 was investigated. The results indicate that the enrichment factor increased with the $\mathrm{pH}$ increase from 2 to 7. When the $\mathrm{pH}$ further increased, the enrichment factors of analytes decreased markedly. This is probably due to the large solubility of sulfonamides in acidic and basic aqueous phase. Thus, no $\mathrm{pH}$ adjustment was done, which is also simple to prepare the sample solution.

Evaluation of DLLME method: Chromatograms of the standards and honey sample are shown in (Fig. 2). The chromatograms were characterized by symmetrical peak shape.
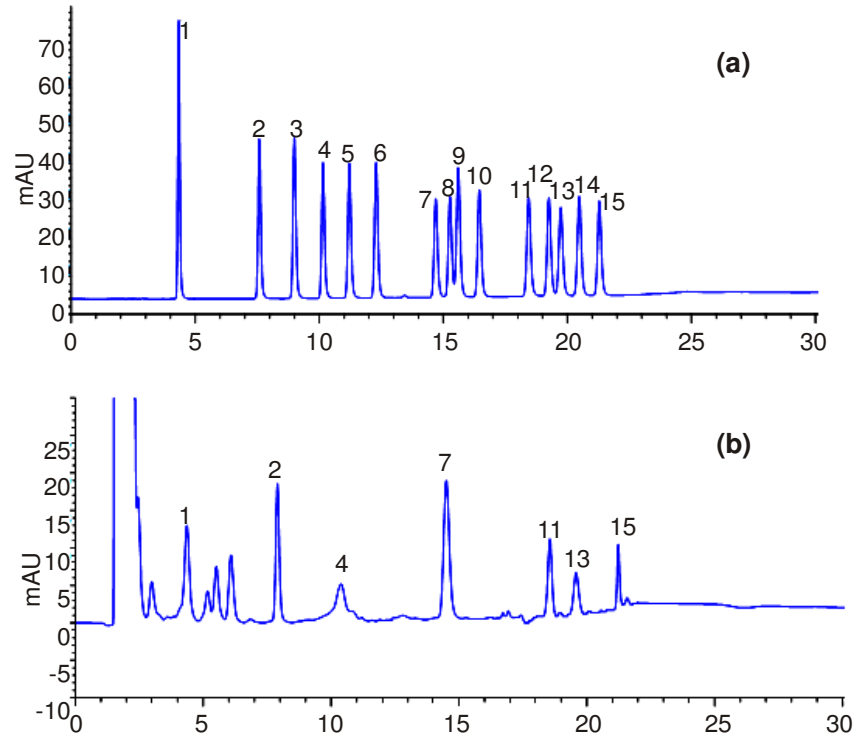

Fig. 2. HPLC chromatogram of standard (a) and honey sample after performing DLLME (b). Extraction conditions: sample volume, $5 \mathrm{~mL}$; extraction solvent, $40 \mu \mathrm{L} \mathrm{C} \mathrm{C}_{2} \mathrm{H}_{2} \mathrm{Cl}_{4}$; dispersive solvent $1.0 \mathrm{~mL}$ acetonitrile. sulfanilamide (1), sulfacetamide (2), sulfadiazine (3), sulfathiazole (4), sulfapyridine (5), sulfamerazine (6), sulfameter (7), sulfamethizol (8), sulfamethazine (9), sulfamethoxypyridazine (10), sulfachloropyridazine (11), sulfamethoxazole (12), sulfamonomethoxide sodium hydrate (13), sulfadoxine (14), sulfisoxazole (15)

Quantitative aspects: Linearity, LOD, LDQ and precision were investigated to validate DLLME for the quantitative analysis of three sulfonamides in honey samples under the above optimal conditions (Table-1). A fairly linear relationship in the concentration range of $0.1-10.0 \mu \mathrm{g} \mathrm{mL}^{-1}$ was observed with a linear regression coefficient higher than 0.9997 for each analytes. The limit of detection (LOD) and the limit of quantification (LDQ) were determined at a signal-to-noise ratio of about 3 and 10, respectively. The LOD and LOQ of the three analytes were $0.8-1.7$ and $2.5-5.3 \mu \mathrm{g} \mathrm{L}^{-1}$, respectively. The

TABLE-1

QUANTITATIVE RESULTS OF SULFONAMIDES BY DLLME

\begin{tabular}{|c|c|c|c|c|c|c|c|c|}
\hline \multirow[b]{2}{*}{ Compound } & \multirow[b]{2}{*}{ Regression equation } & \multirow{2}{*}{$\begin{array}{c}\text { Linear } \\
\text { range } \\
\left(\mu \mathrm{g} \mathrm{mL}^{-1}\right)\end{array}$} & \multirow[b]{2}{*}{$r^{2}$} & \multirow[b]{2}{*}{$\begin{array}{c}\text { LOD } \\
\left(\mu \mathrm{g} \mathrm{L}^{-1}\right)\end{array}$} & \multirow[b]{2}{*}{$\begin{array}{c}\text { LOQ } \\
\left(\mu \mathrm{g} \mathrm{L}^{-1}\right)\end{array}$} & \multirow[b]{2}{*}{$\begin{array}{l}\text { Enrichment } \\
\text { factor }\end{array}$} & \multicolumn{2}{|c|}{ Precision (RSD, \%) } \\
\hline & & & & & & & $\begin{array}{l}\text { Intra-day } \\
(n=6)\end{array}$ & $\begin{array}{c}\text { Inter-day } \\
(\mathrm{n}=3)\end{array}$ \\
\hline Sulfanilamide & $Y=54.894 X^{a}+0.2098$ & $0.01-10.0$ & 0.9997 & 0.8 & 2.5 & 64 & 0.421 & 0.312 \\
\hline Sulfacetamide & $Y=40.382 X-0.6954$ & $0.01-10.0$ & 0.9999 & 1.5 & 4.3 & 73 & 0.172 & 0.118 \\
\hline Sulfadiazine & $Y=42.058 X+0.2621$ & $0.01-10.0$ & 0.9999 & 1.3 & 4.1 & 81 & 1.549 & 1.203 \\
\hline Sulfathiazole & $Y=38.005 X-0.4322$ & $0.01-10.0$ & 0.9999 & 1.7 & 5.0 & 59 & 0.416 & 0.574 \\
\hline Sulfamerazine & $Y=42.976 X-0.1201$ & $0.01-10.0$ & 1.0000 & 1.6 & 5.2 & 75 & 1.284 & 0.973 \\
\hline Sulfameter & $Y=35.552 X-0.6701$ & $0.01-10.0$ & 1.0000 & 0.9 & 2.8 & 61 & 0.448 & 1.063 \\
\hline Sulfamethizol & $Y=33.970 X-0.7557$ & $0.01-10.0$ & 0.9999 & 1.6 & 5.0 & 77 & 0.176 & 0.656 \\
\hline Sulfamethazine & $Y=40.537 X-0.9437$ & $0.01-10.0$ & 1.0000 & 1.0 & 2.9 & 78 & 0.640 & 1.046 \\
\hline Sulfamethoxypyridazine & $Y=39.551 X+0.9282$ & $0.01-10.0$ & 0.9999 & 0.9 & 2.6 & 58 & 1.022 & 0.944 \\
\hline Sulfachloropyridazine & $Y=33.913 X+1.1149$ & $0.01-10.0$ & 0.9999 & 1.7 & 5.3 & 74 & 0.465 & 1.643 \\
\hline Sulfamethoxazole & $Y=36.975 X-0.7805$ & $0.01-10.0$ & 1.0000 & 1.2 & 3.5 & 60 & 0.491 & 1.049 \\
\hline Sulfadoxine & $Y=39.516 X-0.7989$ & $0.01-10.0$ & 0.9999 & 0.9 & 3.0 & 67 & 0.333 & 0.785 \\
\hline Sulfisoxazole & $Y=32.752 X-0.8845$ & $0.01-10.0$ & 0.9999 & 0.8 & 2.7 & 52 & 0.266 & 1.036 \\
\hline
\end{tabular}


TABLE-3

COMPARISON OF DLLME WITH SPE FOR THE DETERMINATION OF SULFONAMIDES IN HONEY SAMPLES

\begin{tabular}{lccccc}
\hline \multicolumn{1}{c}{ Method } & Linearity $\left(\mu \mathrm{gL}^{-1}\right)$ & $\mathrm{LOD}\left(\mu \mathrm{g} \mathrm{L}{ }^{-1}\right)$ & RSD $(\%)$ & Extraction time $(\mathrm{min})$ & Reference \\
\hline SPE-HPLC-UV & $0.002-0.1$ & $1-2$ & $1.76-12.4$ & 45 & 8 \\
SPE-HPLC-UV & $0.25-2$ & $3.3-4.6$ & $4-6$ & 30 & 22 \\
SPE-HPLC-MS & $0.005-0.1$ & 5 & $3.3-11.9$ & 90 & 23 \\
DLLME-HPLC-DAD & $0.01-10.0$ & $0.8-1.5$ & $1.35-3.12$ & A few seconds & Represented method \\
\hline
\end{tabular}

intra-day and inter-day precisions were investigated by determining a mixed standard solution in six replicates during a single day and by duplicating the experiments on 3 consecutive days. Apart from these, the extraction efficiency of DLLME for each analyte was investigated and found the enrichment factors of the sulfonamides ranged from 42 to 81 under the optimal conditions.

Real samples analysis: The honey samples from supermarket were analyzed using to investigate the applicability of the proposed method under optimized conditions. The results showed in Table-2 that sulfanilamide, sulfacetamide, sulfathiazole, sulfameter, sulfachloro-pyridazine, sulfamonomethoxide sodium hydrate and sulfisoxazole were founded in the honey sample. According to the results of recoveries of sulfanilamides, all the samples showed negligible matrix effect. So, the DLLMEHPLC-DAD method is feasible for quantitative analysis of sulfanilamide, sulfadimidine and sulfamethyl-isoxazole in real samples and could be used in routine analysis.

\begin{tabular}{lccc}
\multicolumn{4}{c}{ TABLE-2 } \\
\multicolumn{4}{c}{ ANALYTICAL RESULTS IN REAL HONEY SAMPLES } \\
\hline \multicolumn{1}{c}{ Compound } & $\begin{array}{c}\text { Found } \\
\left(\mu \mathrm{g} \mathrm{kg}^{-1}\right)\end{array}$ & $\begin{array}{c}\text { Recovery } \\
(\%)\end{array}$ & RSD $(\%)$ \\
\hline Sulfanilamide & 3.21 & 79.4 & 3.5 \\
Sulfacetamide & 4.54 & 81.7 & 4.2 \\
Sulfadiazine & $\mathrm{ND}^{\mathrm{a}}$ & 82.2 & 6.3 \\
Sulfathiazole & 6.27 & 89.9 & 5.4 \\
Sulfapyridine & $\mathrm{ND}$ & 90.6 & 5.9 \\
Sulfamerazine & $\mathrm{ND}$ & 93.4 & 6.7 \\
Sulfameter & 7.11 & 95.3 & 3.8 \\
Sulfamethizol & $\mathrm{ND}$ & 97.1 & 5.1 \\
Sulfamethazine & $\mathrm{ND}$ & 96.7 & 4.3 \\
Sulfamethoxypyridazine & $\mathrm{ND}$ & 90.57 & 2.4 \\
Sulfachloropyridazine & 3.43 & 93.98 & 3.3 \\
Sulfamethoxazole & ND & 88.48 & 2.4 \\
Sulfamonomethoxide & 2.90 & 88.07 & 2.2 \\
Sodium Hydrate & $\mathrm{ND}$ & 88.77 & 3.1 \\
Sulfadoxine & 2.37 & 95.71 & 2.5 \\
Sulfisoxazole & & & \\
\hline${ }^{a}$ ND = Not detected. & & &
\end{tabular}

Comparison of DLLME with SPE: The extraction efficiencies of analytes by DLLME-HPLC-DAD were compared with other reported methods such as SPE-HPLC-UV ${ }^{8,22}$ and SPE-HPLC-MS ${ }^{23}$ from the viewpoint of the extraction time, relative standard deviation (RSD), limits of detection (LOD) and linear range (LR). As listed in Table-3, DLLME showed lower RSD (0.172-1.549\%) and LODs (0.8-1.7 $\left.\mu \mathrm{g} \mathrm{L}^{-1}\right)$ and much wider linear range, $\left(0.01-10.0 \mu \mathrm{g} \mathrm{mL}^{-1}\right)$ in comparison with SPE-HPLC. Additionally, the extraction time for the DLLME is very short and does not require special approach and instrument in the pretreatment step. Therefore, it is very simple, rapid, inexpensive, easy to use and benign to the environment.

\section{Conclusion}

In this study, a simple, rapid, and inexpensive DLLMEHPLC-DAD method was proposed for the determination of sulfanilamides in honey sample. The conditions of extraction performance have been optimized. The experimental results reveal that this method had many practical advantages such as high enrichment factor within a short time, lower solvent consumption, higher enrichment factor and good linearity over the investigated concentration range. Therefore, the performance of this procedure in the extraction of sulfanilamides from honey samples was satisfactory.

\section{ACKNOWLEDGEMENTS}

The work was supported by the Knowledge Innovation Programs of the Chinese Academy of Sciences (No. KSCX2EW-J-26)

\section{REFERENCES}

1. C. Hartig, T. Storm and M. Jekel, J. Chromatogr. A, 854, 163 (1999).

2. P.S. Milne, Nature, 155, 335 (1945).

3. C.A. Thomson and P. Sponrns, J. Food Sci., 60, 409 (1995).

4. H.B. Sheth, V.A. Yaylayan, N.H. Low, M.E. Stiles and P. Sporns, J. Agric. Food Chem., 38, 1125 (1990).

5. N.P. Navarro, E.G. Iglesias, A. Maquieira and R. Puchades, Talanta, 71, 923 (2007).

6. E. Neidert, Z. Baraniak and A. Sauvé, J. Assoc. Off. Anal. Chem., 69, 641 (1986).

7. J. Sherma, W. Bretscnieder, M. Dittamo, N. DiBiase, D. Huh and D.P. Schwartz, J. Chromatogr. A, 463, 229 (1989).

8. K.E. Maudens, G.F. Zhang and W.E. Lambert, J. Chromatogr. A, 1047, 85 (2004).

9. G. Stoev and A. Michailova, J. Chromatogr. A, 871, 37 (2000).

10. K. Kishida and N. Furusawa, J. Chromatogr. A, 937, 49 (2001).

11. M. Rezaee, Y. Assadi, M.M. Hosseini, E. Aghaee, F. Ahmadi and S. Berijani, J. Chromatogr. A, 1116, 1 (2006).

12. M.A. Farajzadeh, M. Bahram and J.Å. Jönsson, Anal. Chim. Acta, 591, 69 (2007).

13. H. Chen, J. Ying, H. Chen, J. Huang and L. Liao, Chromatographia, 68, 629 (2008).

14. K. Farhadi, M.A. Farajzadeh, A.A. Matin and P. Hashemi, Cent. Eur. J. Chem., 7, 369 (2009).

15 . C. Xiong, J. Ruan, Y. Cai and Y. Tang, J. Pharm. Biomed. Anal., 49, 572 (2009)

16. M. Rezaee, Y. Yamini, S. Shariati, A. Esrafili and M. Shamsipur, J. Chromatogr. A, 1216, 1511 (2009).

17. E.Z. Jahromi, A. Bidari, Y. Assadi, M.R.M. Hosseini and M. Jamali, Anal. Chim. Acta, 585, 305 (2007).

18. M.A. Farajzadeh, M. Bahram, B.G. Mehr and J.A. Jönsson, Talanta, 75, 832 (2008).

19. P. Liang, E. Zhao and F. Li, Talanta, 77, 1854 (2009).

20. H. Chen, H. Chen, J. Ying, J. Huang and L. Liao, Anal. Chim. Acta, 632, 80 (2009).

21. P. Liang, J. Xu and Q. Li, Anal. Chim. Acta, 609, 53 (2008).

22. R.H.M.M. Granja, A.M.M. Niño, F. Rabone and A.G. Salerno, Anal. Chim. Acta, 613, 116 (2008).

23. T.S. Thompson and D.K. Noot, Anal. Chim. Acta, 551, 168 (2005). 